Este artigo apresenta as discussóes resultantes de nossa dissertação de mestrjdo na qual investigamos os traços marcantes da posição subjetiva dos mestres de adolescentes que conseguem realizar sua tarefa educativa, incluindo-a no campo de uma "missão possível". Atrayés da análise do referencial psicanalítico de entrevistas com alguns destes professores, pudemos concluir que o "bom professor de adolescentes" apresenta uma especial posição subjetiva em seu ato de transmissão. Especial posição subjetiva que comporta importantes aspectos: a arti culação entre lei e desejo; uma relação diferenciada com a "causa adolescente", o valor subjetivo simbólico atribuído à função de mestre; e a possibilidade de "circulação discursiva" no ato de transmissão. Adolescência; psicanálise; professores; educação; interação professor-aluno

THE IIMIPOSSIBLE ADOLESCENTS' MASTER AN SPECIAL SUBJECTIVE POSITION DURING THE TRANSMISSION ACT

This article presents the discussions resulting from our master's dissertation where we investigate the mainly traces of the adolescent masters' subjective position who are successtul on their educational task, by including it in the field of an "possible mission". Through the analysis under the psychoanalytical referential of the interviews made with some of these: teachers, we came to the conclusion that the good adolescent teacher" reveals an special subjective position during the transmission act. Special subjective position supporting importants aspects: the articulation between the law and the desire, the differentiate relationship under an adolescent concern; the symbolic subjective value done to the mastership and the possibility of

circulation of the speech during the transmission proceedings.

Adolescence;

psychoanalysis, teacher education; teacher-student relationship

\section{O MESTRE (IM)POSSÍVEL DE ADOLESCENTES - UMA ESPECIAL POSIÇÃO SUBJETIVA NA TRANSMISSÃO}

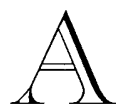

clínica psicanalítica de adolescentes é povoada por "pequenos grandes dilemas". Discursos inflamados sobre a conturbada relação com os pais, as primeiras paixões, as grandes decepções, os ideais em plena construção são facetas do processo adolescente de construir uma assertiva sobre si mesmo, visando a uma escritura singular.

Dentre estes dilemas, a relação com o professor. Personagem-alvo de amor e ódio desde os tempos da juventude de Freud: "Nós os cortejávamos ou lhes virávamos as costas; imaginávamos neles simpatias e antipatias que provavelmente não existiam; estudávamos seus caracteres e sobre estes formávamos ou deformávamos os nossos. (...) Estáva-

Psicanalista; Mestre em Psicologia pelo Instituto de Psicologia da Universidade de São Paulo (IPUSP); Professora da Universidade São Marcos e Faculdade Taboão da Serra; Psicóloga Escolar da Prefeitura Municipal de Guarulhos. 
mos, desde o princípio, igualmente inclinados a amá-los e a odiálos, a criticá-los e a respeitá-los." (1914, p. 286).

Muita história transcorreu desde os tempos freudianos até o nosso segundo milênio. Se àquela época os professores de adolescentes viviam algumas dificuldades, atualmente eles lidam com situações muito mais sérias de indisciplina, violência, abandono e fracasso escolar. A tarefa educativa de adolescentes tem sido da ordem de uma "missão impossível".

(Im)possibilidade resultante da situação da escola e da educação na modernidade, articulada ao processo psíquico específico do adolescente em relação ao saber vindo do campo do Outro.

Kupfer (2000) afirma que o professor brasileiro não mais encontra uma rede de sustentação social e simbólica para o exercício de seu mandato. Rede esta que remeteria os sujeitos a uma tradição e a significações que poderiam contribuir para uma ressignificação do futuro. O professor encontra-se extremamente solitário, numa tentativa hercúlea de sustentar, em nome próprio, seu lugar de referência e de representante da cultura construída ao longo dos séculos.

Nesta situação o professor tem sucumbido à castração imaginária ao qual é lançado, sofrendo por causa da sua condição financeira e social, identificando-se com esta menor valia e sentindo-se impotente em sua função educativa. Passa a exercer a docência de forma burocrática e automática, forcluindo seu desejo e de seus alunos.

O adolescente, por sua vez, é nomeado "aborrescente", marginal e indisciplinado pelo discurso social/escolar. Nomeação que empurra para a vala da exclusão a sua palavra, os seus dizeres, as suas criações e as suas singularidades. Vala que mortifica o sujeito desejante...

Por outro lado, o que está em jogo é o processo psíquico específico da adolescência. $O$ adolescente descobre a falácia da promessa edípica, que lhe indicava que o gozo ao qual renunciou na infância seria restituído quando crescesse.

Segundo Almeida (2000) o adolescente apresenta um "saber em excesso" que o adulto/professor já recalcou. O adolescente percebe esta falácia, o impossível incluído na relação sexual, ou seja, o impossível da completude prometida na infância. Desconfia do mundo, dos ideais transmitidos e, principalmente, dos grandes representantes destes ideais do mundo adulto - os professores. Sobre a impossibilidade do controle de chegar a resultados ideais, absolutos, completos, os adolescentes "sabem muito bem" e atuam desnudando o mestre que insiste neste impossível, apresentando-se como "Todo". 
"Todo" que remete à posição dos pais da infância. $\mathrm{Na}$ adolescência há uma torção que implica deixar de responder a partir da posição infantil de certa submissão e alienação aos pais para, então, tornar-se causa do desejo de um outro qualquer.

Tempo em que o jovem verifica que "há algo de podre no reino do pai". Sente que o mundo o deixou só, desconfiando daqueles que até então o tratavam como "Sua Majestade, o bebê". Há uma virada em relação ao saber vindo do Outro, em relação à veracidade e à consistência deste saber, com conseqüências marcantes para a relação transferencial com o professor.

Esta relação é permeada pela questão imaginária: até que ponto este professor é, ou não, um aliado dos pais. Diante deste mote, o adolescente passa a testar impiedosamente a consistência deste Outro/professor.

Há, também, uma enorme luta psíquica do adolescente para não sucumbir à posição infantil que implica certa submissão aos caprichos e ingerências dos pais. Neste sentido, o professor que tenta submeter o adolescente aos seus caprichos narcísicos encontra-se diante de uma situação delicada.

Diante destas articulações podemos pensar que não há esperanças. No entanto, os próprios adolescentes indicam as saídas.

Em suas análises são freqüentes os comentários sobre os professores que envolvem o grupo e conseguem promover aulas interessantes, transmitindo o conteúdo formal com sucesso sendo, por este fato, respeitados pelos alunos.
Ao ministrar Cursos de Formação de Professores ${ }^{1}$, tive a oportunidade de ouvir relatos de professores extremamente implicados, transmitindo suas experiências riquíssimas e de grande sucesso no ensino para adolescentes.

Diante destes relatos, ouso incluir a educação de adolescente no campo de uma "missão possível". Missão situada muito além das semelhanças ou diferenças entre os métodos e técnicas pedagógicas. Há, na verdade, uma "especial posição subjetiva" do mestre de adolescente que consegue cumprir com sucesso sua função educativa.

Posição subjetiva que, segundo a psicanálise, revela-se no discurso, em suas entrelinhas, nas repetições significantes, nos sentidos advindos do desdobramento discursivo, nas enunciações que se desprendem dos enunciados.

Neste sentido entrevistei três professores, dois ministrando aulas em escolas públicas e um outro ensinando em uma escola particular, todos eleitos por seus alunos e coordenadores como bons professores de adolescentes. A análise das entrevistas foi conduzida a fim de verificar em seus discursos os possíveis traços que comporiam esta "especial posição subjetiva” na transmissão.

Prontamente todos aceitaram o convite para relatar as particularidades de seu trabalho. Pareciam sedentos para descrever suas experiências, suas conquistas e seus questionamentos, utilizando o espaço da entrevista para repensar sua prática, de uma maneira extremamente implicada e apaixonada. Não se intimidaram nem 
se colocaram como objeto passivo de estudo do entrevistador. Estavam ali como sujeitos do próprio discurso e da própria prática, querendo transmitir ao entrevistador a "magia" de sua ação pedagógica e, na transferência com o entrevistador, construir um saber sobre esta ação.

Sigamos agora a trilha discursiva desses "mestres possíveis de adolescentes". Apresento aos leitores a análise geral das entrevistas, ressaltando os eixos comuns entre elas e incluindo algumas citaçōes.

\section{O PAPEL DE MESTRE TEM VALOR!}

O lugar de professor de adolescentes apresenta-se como uma escolha essencial na vida desses professores, constitui uma nomeação, um traço de identificação marcado "a ferro e fogo". Escolha guiada pelo desejo. E é este desejo que, por sua vez, permite a sustentação do valor simbólico do papel do professor.

Uma escolha marcada pela paixão de formar: "gosto do que faço, acho que eles percebem isto"; "acho que tenho muito orgulho de dar aula". O lugar de professor compõe o Ideal-de-Eu dos próprios professores. Assim a "potestade" do professor está mantida, sendo pouco abalada pelos "testes" dos adolescentes, ou contaminada pelo discurso depressivo dos colegas de profissão.

Estes professores não sucumbem à desvalorização de seu papel na modernidade, apesar de reco- nhecê-la. A partir deste valor simbólico atribuído ao lugar de professor, conseguem sustentar a lei e o dever na relação educativa, apresentando-se como plenamente responsáveis por sua função e exigindo também uma responsabilidade por parte dos alunos.

Todos eles demonstram certa rigidez no cumprimento das propostas educativas e das regras combinadas. Não se deixam abalar pelas "ameaças do aluno" e reagem sempre de forma firme e segura. Em nenhum momento relatam a necessidade de contar com o diretor ou coordenador para que as regras do jogo educativo sejam cumpridas.

Isto parece essencial, pois freqüentemente o adolescente "testa" a consistência do professor (consistência do Outro), enquanto lugar de representante da lei social e enquanto possível referência. Os professores entrevistados sustentam a lei, não para submeter os alunos ao próprio narcisismo, mas para responsabilizá-los pelas regras do processo educativo.

Apresentam ao adolescente uma dimensão de responsabilidade, confrontando-os com o discurso social, sem entrar em embates imaginários. Neste sentido, o discurso desses professores é atravessado pela certeza do valor simbólico de seu papel a partir do qual lidam com os testes dos adolescentes e com a desvalia imaginária do papel de mestre na atualidade. Caso contrário, sucumbiriam à impotência imaginária.

Esfinge, por exemplo, não se sente ameaçada por seus alunos - muitos deles traficantes -, pois descreve ter "segurança". Segurança advinda da 
clareza de sua função simbólica enquanto professora e também em relação ao laço e respeito que adquiriu junto à comunidade escolar. Alcançou o valor simbólico do papel de professor numa escola em condições extremamente precárias. Walter estabelece funções claras desde o início do curso e as sustenta - "eu não quebro a regra" -, e Sônia exige ser chamada por "senhora" e que sejam cumpridas as atividades escolares.

No entanto, se esses professores ficassem apenas na posição de representantes da lei, meramente cumprindo seu dever, estaríamos diante de uma educação superegóica, insuportável para o adolescente que coloca em cheque o mundo adulto e seus mandatos.

Esses professores sustentam seu lugar de mestria e de representantes da lei simbólica, para inserir o aluno na aprendizagem e não para submetê-lo à sua própria satisfação narcísica. Esfinge é bastante clara ao dizer ao aluno: "estou aqui para o seu bem!". Não para o bem dela.

Além de tornarem seus alunos responsáveis pelo processo educativo e por suas regras, tais mestres oferecem espaço para que, dentro das possibilidades, os alunos manifestem-se subjetivamente por meio das redações ou das discussões sobre os conteúdos ministrados e sua relação com temas da adolescência. Incluem os dizeres e opiniões de seus alunos.

Sustentam em seus discursos o valor atribuído à função do professor. Sendo o lugar do mestre um Ideal-de-Eu para o próprio professor, abrem espaço para que o aluno coloque-os nesta posição essencial 


\section{Dossiê}

para que os professores possam concretizar sua transmissão.

Conseguem, então, articular lei e desejo na transmissão. Trata-se de uma articulação essencial entre o valor simbólico de sua transmissão e o sujeito desejante presente nos próprios professores e em seus alunos.

\section{A ADOLESCÊNCIA DOS PROFESSORES E A DIMENSÃO DA APOSTA}

A escolha profissional - "ser professor" - foi a nomeação resultante do processo adolescente de cada um dos professores. Segundo Rassial (1995), a escolha profissional é a tentativa de construção de um novo nome-do-pai, lembrando que este engendramento de novos nomes-do-pai é um processo tipicamente adolescente, processo de ressignificação da história pessoal no campo da filiação $e$ de inscrição no laço social.

É interessante notar que, para os três professores entrevistados, esse processo foi atravessado pela relação com seus professores da adolescência.

Temos como exemplo o caso de Esfinge, que foi "resgatada" enquanto sujeito pensante e desejante em sua relação com seus professores de História e Psicologia no tempo ginasial. Além disso, segundo sua própria análise, viveu sua adolescência na "tribo" dos "filiados" ao partido político outrora apresentado pela professora de História. Oriunda de família que exigia apenas sua freqüência à escola, sem sérias preocu- pações quanto ao seu futuro, ou quanto ao dos outros filhos, Esfinge obteve a filiação simbólica através da figura de seus professores, que, segundo ela, a "adotaram", orientando-a e contribuindo para sua inscrição no laço social.

Esta articulação entre a escolha profissional e o processo adolescente de cada professor, tendo como figura importante professores da própria adolescência, repete-se claramente no discurso dos outros professores e constitui o vetor da sua relação com seus alunos adolescentes.

Assim como puderam contar com seus professores, eles se oferecem para seus alunos enquanto "adultos com quem se pode contar”.

Transmitem, através da função de "amigo" - termo reincidente em todas as entrevistas -, a possibilidade de que seus alunos encontrem suas próprias saídas. Fazem os alunos perceberem que "nem tudo é podre no reino do pai”, sendo possível a construção de uma marca pessoal e uma nomeação que insira o adolescente no laço social.

Temos, então, no discurso desses professores, a dimensão da aposta na condição de sujeito desejante dos adolescentes - sujeito de seus destinos e da aprendizagem.

O lugar de amigo que descrevem não é similar ao amigo como um "igual" imaginário. Trata-se de um lugar de acolhimento, de "esteio", como descreve Walter, destinatário do discurso adolescente. São sensíveis às necessidades dos alunos e capazes de fazer a "leitura" (termo utilizado por Walter) das encenações e demandas adolescentes. 
Além disso, valorizam o conteúdo programático sempre buscando suas articulações com a vida dos alunos, com as suas experiências e necessidades. Sônia consegue explicar o valor da "oração subordinada" para que o adolescente possa se inserir no mercado de trabalho; Walter colhe "as palavras" do adolescente no início da aula e Esfinge preocupa-se em respeitar "a letra do seu aluno".

Nesse sentido, a funçāo educativa está atravessada pelo lugar de referência e de auxiliar no processo de constituição subjetiva de seus alunos adolescentes. Atravessamento possível em função da história pessoal de cada professor.

\section{A ADOLESCÊNCIA NA VISÃO DOS PROFESSORES}

A visão dos professores entrevistados sobre a adolescência é bastante diferenciada daquela encontrada no discurso social/escolar que circunscreve a adolescência como um tempo apenas de crise, de "aborrescência" e de marginalidade.

$\mathrm{O}$ adolescente é visto como engraçado, criativo, porém necessita de atenção, esteio e referência de pessoas que possam estar numa posição de orientador (formador). Os adolescentes são encarados, ainda, como aptos para aprender, detentores de um saber próprio. Possuem uma visão crítica sobre o mundo e são capazes de se responsabilizarem por seus atos e palavras.
Todos os professores possuem uma relação de cumplicidade e certa intimidade com os alunos. No entanto, sustentam os limites, fruto da clareza da posição de professor e do lugar simbólico que representam. Apesar da grande proximidade que permitem ao aluno, são respeitados nos momentos em que o aluno deve "cumprir sua função e o professor a dele", como declara Walter.

São professores sensibilizados com as questões da adolescência e oferecem espaço para que sejam discutidas durante alguns momentos na sala de aula, sem abdicar de sua função enquanto responsável pela transmissão de conteúdos formais.

O termo "identificação" surgiu em todas as entrevistas, articulado, por um lado, à compreensão do processo adolescente e, por outro, ao processo de ressignificação da própria adolescência dos professores na relação com seus alunos. Citamos Esfinge, que relata ter sido muito séria em sua adolescência, o que a levou a valorizar o aspecto lúdico e brincalhão de seus alunos.

Esses professores, então, transmitem aos seus alunos a possibilidade de construir suas significações, tanto no campo da aprendizagem, quanto no campo subjetivo. Enfocam, principalmente, o saber do aluno e a articulação do saber da cultura às questões adolescentes.

A partir da sustentação do lugar de referência articulada à transmissão da dimensão da aposta na possibilidade discursiva de seus alunos, esses professores conseguem produzir um efeito grupal importante no processo adolescente. 


\section{Dossiê}

Sônia e Esfinge descrevem situações em que um aluno chama a atenção do outro, quando este está "pisando na bola" com o professor. O professor, então, consegue ser tomado como líder, alguém respeitável no grupo (Ideal-de-Eu) sendo sua palavra importante e digna de ser ouvida.

São professores sensiveis à causa adolescente, que se oferecem enquanto lugar para o qual o adolescente possa remeter seu discurso.

\section{A TRANSMISSÃO É VIVA}

A relação desses professores com sua função e com as atividades e conteúdos transmitidos é marcada por uma extrema vivacidade. Na entrevista de Sônia é freqüente a palavra "busca": busca da aprendizagem, busca do aluno. Ou, como podemos constatar na entrevista de Esfinge, apesar de ela julgar menos importante o conteúdo formal (oficial), ministra-o procurando enfatizar o pensamento reflexivo, tornando a transmissão tão envolvente que suas salas ficam cheias e os alunos resistem à necessária interrupção da atividade com a qual estão envolvidos, ao término da aula. Walter, por sua vez, descreve um "arrepio" ao trabalhar com os temas de História.

Esses professores subjetivam o conteúdo transmitido. Transmitem o conteúdo de forma viva, envolvente, pois ele é considerado importante pelo próprio professor. O resultado é a "conquista do aluno" [sic] (Sônia).

Esta relação com o saber e com o ensinar, marcada pelo desejo que a torna viva, parece possibilitar a transmissão de um desejo de saber para os alunos. São professores que produzem uma transferência de trabalho, pois eles estão constantemente a trabalhar, a buscar novas significaçōes. A relação com o ensinar é permeada pelo aprender constante. Daí ser possível que os alunos, olhando para um adulto em processo de ressignificar e trabalhar com os conteúdos de forma viva, possam fazê-lo também, envolvendo-se com o processo de aprendizagem.

Para o adolescente, este aspecto é essencial, pois a transmissão do saber é marcada não por uma tentativa de subjugaçāo aos conteúdos formais - o que enfureceria certos adolescentes -, mas pela possibilidade de construção de "coisas novas" com estes conteúdos. Apesar da diferença metodológica, todos os três transmitem este interesse em relação ao saber, engatando o aluno no processo educativo.

O professor também está marcado por uma "falta que o faz trabalhar para saber". Esta posição subjetiva que marca o processo 
desejante desses professores é transmitida na relação com o aluno. Transmite-se a possibilidade de ser mestre de um saber, ou seja, de aprender, pois a este processo é atribuído um valor subjetivo a quem está na posição de professor.

Dessa forma, os professores entrevistados apresentam-se para os alunos também marcados pela falta, pela castração, "não sabendo tudo", como diz Sônia; ou como Esfinge, quando requer o pensamento crítico de seus adolescentes. Esta "castração simbólica" ativa a instauração de um processo marcado pelo desejo e a transmissão de que, apesar da castração, podem-se buscar nomeações e sentidos que inclusive dêem conta daquilo com que o adolescente se depara: a impossibilidade da relação sexual.

\section{CIRCULAÇÃO DISCURSIVA}

No discurso dos professores entrevistados era revelada uma articulação entre duas posições: ser professor e ser amigo, conforme ressaltamos anteriormente. Os adolescentes traduzem este aspecto ao dizerem que Sônia é "profissional e é legal".

Articulação que remete à justificativa de Esfinge sobre sua facilidade em relação ao ensino de adolescentes: "Acho que é porque eu circulo em sala de aula". Trata-se, na verdade, de uma circulação discursiva.

Os mestres entrevistados situam-se, sim, no Discurso do Mestre, sustentando a lei, falando de um lugar de saber. Posição discursiva que implica o não-aparecimento do sujeito da castração. Ao falar, eles crêem-se sem falhas, acreditam, ilusoriamente, ser mestres de tudo o que dizem, assumindo um lugar de modelo e de um adulto que, diante do aluno, se supõe "Todo".

No entanto, ao convocarem o aluno e seu saber para o processo de aprendizagem, apresentam-se, discursivamente, como um mestre "não-todo", matizados pelo Discurso Analítico, no sentido de sustentar certa castração simbólica. Colocam-se de forma a permitir que os alunos entrem no processo de aprendizagem na posição de sujeitos desejantes, capazes de ser mestres de um saber.

Os alunos são autorizados a se situar no Discurso do Mestre, por exemplo, ao falarem sobre o que sabem a respeito da matéria ou sobre suas opiniões a respeito dos fatos históricos. Os professores entrevistados sustentam, em sua transmissão, o lugar de mestria "não-toda", permitindo que o aluno se implique e construa novas significações e conhecimentos através do que foi ensinado.

Um professor que porta a palavra de uma geração - Discurso 
do Mestre. No entanto, é um professor que permite, e até provoca, que a construção continue a ser tecida por seus alunos, possibilitando giros discursivos.

Mestres que, apesar de se posicionarem como sabedores e representantes da lei, conhecem seu lugar de semblante deste saber, do lugar vazio que ocupam, através do qual o aluno tecerá seu próprio saber. Uma posição marcada pela falta - Discurso Analítico -, para que o desejo possa circular e produzir seus efeitos.

Este traço de posicionamento subjetivo parece essencial no caso do professor de adolescentes. Adolescentes que sabem da impossibilidade da completude são "cruéis" com os professores que se apresentam como "todo". No caso dos professores entrevistados, deparamo-nos com adultos em posição de transmissão, advertidos de que no Outro há esta falta que nenhum saber pode vir a completar, possibilitando, a partir daí, que se crie algo interessante na relação educativa.

\section{MOMENTO DE CONCLUIR}

Momento de concluir sobre o (im)possível "sucesso escolar", num tempo em que as pesquisas buscam a compreensão dos mecanismos do fracasso escolar.

Nosso trabalho com professores permitiu que tivéssemos contato com profissionais entusiasmados, que relatam experiências extremamente positi- vas em sua prática, apontando para inúmeras "possibilidades" no campo da educação de adolescentes.

Professores com a respeitabilidade de verdadeiros Mestres. Mestres que, a partir do valor simbólico que atribuem à própria função, conseguem articular de forma brilhante a lei e o desejo em sua transmissão, implicando-se e implicando os alunos no processo educativo.

Mestres cuja postura na transmissão permite ao aluno lidar com o conhecimento através seu próprio estilo, produzindo algo que este último reconhece como próprio. Para tanto se apresentam como "mestre não-todo”, abrindo espaço para a circulação discursiva e o aparecimento de estilos próprios.

Mestres bastante ocupados com a formação de seus alunos, para quem as informações são apresentadas como objetos fornecidos pela cultura para que o adolescente possa servir-se deles em seu processo de inscrição no mundo adulto e no laço social.

Mestres sensíveis à "causa adolescente", oferecendo-se enquanto lugar de referencia, para o qual o adolescente remete seu discurso, podendo simbolizar suas encenações, atuações e afrontas. Os adolescentes demonstram ter a certeza de que este mestre é "ao menos um" adulto com quem se pode contar... Um adulto que não impõe seus próprios fechamentos (Rassial, 1999), mas oferece meios discursivos para que o adolescente produza seus próprios fechamentos, sua própria nomeação.

Mestres que incluem a dimensão de aposta no potencial do adolescen- 
te. Potencialidade criativa, discursiva e de aprendizagem. Crença de que o adolescente, apesar deste mundo desacreditado, pode construir uma nomeação própria, ter referenciais e estabelecer laços sociais.

O Homem Mascarado, criação de Weddekind ${ }^{3}$, apresenta a dimensão de aposta em seu diálogo com Melchior, personagem adolescente desesperado, prestes a cometer suicídio:

"Melchior: O senhor diz-me ou não quem é?

Homem Mascarado: Não. Proponho que confies em mim. Cuidaria, em primeiro lugar, da tua subsistência.

Melchior: O senhor é meu pai?

Homem mascarado: Seria capaz de não reconhecer o teu pai pela voz?

Melchior: Não.

Homem Mascarado: O senhor teu pai procura agora consolação nos braços fortes de tua mãe. Eu abro-te as portas do mundo."

Não é o pai, mas faz semblante de sua função, apresentando-se como referência, como suporte, uma autoridade benevolente (Freud, 1910), que aposta no jovem como capaz de fazer algo produtivo de sua vida, a partir do saber que recebe. Um saber "não-todo" que abre as portas para o mundo.

Mestres que, atuando em escolas que permitem a impressão de um estilo próprio de transmissão, sustentam a "condição do saber": "...condição do saber, ou seja, a possibilidade de um sujeito ultrapassar a identificação imaginária à consistência de sentidos de elementos da linguagem por meio do recurso às demarcações simbólicas do laço social que os reduz, de modo que o sujeito possa constituir a sintaxe à qual ele se refira e que o oriente, conquistando, assim, um lugar em que circule na linguagem ao mesmo tempo em que dela se diferencia." (Vorcaro, 2001, p. 113)

\section{Mestres que...}

Finalizamos com a sensação de que há muito, ainda, a ser investigado, e de que nem tudo foi dito.

Condição sine qua non do ser de linguagem.

Seriam estes mestres os eleitos em escolas diferentes? Os traços subjetivos apresentados se repetiriam nos professores de crianças? Como transmitir a "habilidade" desses mestres a outros professores, em se tratando de posição subjetiva? Novas questões... futuras pesquisas pautadas sobre a busca incessante de saber sobre o que está em jogo nos processos adolescentes e em seu laço social.

Cabe agora deixar-nos invadir pelo impossível de ser dito que não cessa de não se escrever, presente no próprio ato da transmissão.

Puro enigma, pura magia...

\section{REFERÊNCIAS BIBLIOGRÁFICAS}

Almeida, S.F.C. (2000). O adolescente e a educação: a função (im)possivel dos ideais educativos. In $O$ adolescente $e$ a Modernidade - Tomo III Congresso Internacional de Psicanálise e suas Conexões. Rio de Janeiro, RJ: Ed. Cia de Freud.

Bernardino, L. M. F. (2000). Letra, identificação e estrutura na adolescência. In $O$ 
Adolescente e a Modernidade - Tomo III. Congresso Internacional de Psicanálise e suas Conexóes. Rio de Janeiro, RJ: Ed. Cia de Freud.

Fink, B. (1998). O sujeito lacaniano: entre a linguagem e o gozo. Rio de Janeiro, RJ: Jorge Zahar.

Freud, S. (1914). Algumas Reflexões sobre a Psicologia do Escolar. In Edição standard brasileira das obras psicológicas completas de Sigmund Freud (J. Salomão, trad.) (Vol. XIII). Rio de Janeiro, RJ: Imago, 1987.

(1910). Suicide in childhood. In

Minutes of the Vienna Psychoanaytic Society (vol II). New York, N.Y.: International University Press Inc., 1967.

Kupfer, M C. M. (2000). Educą̧ão para o futuro. Psicanálise e Educação. São Paulo, SP: Escuta.

Lajonquière, L. (1997). Dos "erros" e em especial daquele de renunciar à educação - Notas sobre Psicanálise e Educação. In Estilos da Clínica: Revista sobre a Infância com Problemas, ano II, $\mathrm{n}^{\mathrm{0}} 2$. São Paulo, SP: IPUSP.

Melman, C. (1995). Haveria uma questão particular do pai na adolescência? In Revista da Associação Psicanalítica de Porto Alegre - Adolescência, ano 5, vol. 11. Porto Alegre, RS: Artes e Ofícios.

Mrech, L. M. (1999). Psicanálise e Educação: Novos operadores de leitura. São Paulo, SP: Pioneira.

Rassial, J-J. (1995). Hipóteses sobre a adolescência. In Revista da Associação Psicanalítica de Porto Alegre - Adolescência, ano 5, vol. 11. Porto Alegre, RS: Artes e Ofícios.

(1999). O adolescente e o Psicanalista. Rio de Janeiro, RJ: Ed. Cia. de Freud.

Vorcaro, A.M.R. (2001). A exclusão do saber. In Estilos da Clínica. Revista sobre a infância com problemas. Vol. VII, n. 10. São Paulo, SP: IPUSP.

\section{NOTAS}

1 Curso organizado e ministrado em 2000 pela equipe técnica da STOIC - Seção Técnica de Orientação e Integração Comunitária da Secretaria Municipal de Educação Prefeitura de Guarulhos, da qual fui integrante.

2 Discussão trazida em aula do curso de mestrado, ministrado pela professora $M$. Cristina Kupfer, ao comentar a experiência da instituição suiça: Courtil.

3 "O despertar da Primavera", de Weddekind (1989) - citação de cópia onde se encontravam ausentes os dados bibliográficos. O texto original não foi localizado. 